\title{
Association between the need for normative and self-perceived dental treatment in young Brazilian students
}

Fernanda Crestina Leitenski Delela ( $\sim$ fernandadelela@hotmail.com )

Universidade Federal do Rio Grande do Norte Centro de Ensino Superior do Serido https://orcid.org/0000-0002-0833-1117

Aline Blaya Martins

Universidade Federal do Rio Grande do Sul

Helenita Correa Ely

Pontificia Universidade Catolica do Rio Grande do Sul

Claides Abegg

Universidade Federal do Rio Grande do Sul

Research article

Keywords: normative dental treatment needs, perceived dental treatment needs, questionnaires, dental caries, gingivitis, trauma, adolescents

Posted Date: November 4th, 2019

DOI: https://doi.org/10.21203/rs.2.16747/v1

License: (c) (1) This work is licensed under a Creative Commons Attribution 4.0 International License. Read Full License 


\title{
Association between the need for normative and self-perceived dental treatment in young Brazilian students
}

\author{
Delela, FCL- Universidade Federal do Rio Grande do Sul (corresponding author) \\ Martins, AB- Universidade Federal do Rio Grande do Sul \\ ELY, HC- Pontíficia Universidade Católica de Porto Alegre \\ Abegg, Claides- Universidade Federal do Rio Grande do Sul
}

\section{Abstract:}

Background: To assess the level of agreement and association between clinical and self-perceived need for dental treatment in adolescents. Methods: A crosssectional study was conducted with 1470 adolescents aged 15-19 years in 36 cities in southern Brazil. The data were collected in 2011 from a questionnaire and clinical oral examination. The clinical criteria used to determine the need for dental treatment were the positive result of clinical examination for one or more variables of presence of caries, gingival bleeding, trauma, need for restorative treatment and need for aesthetic treatment. The question: "Do you think you currently need dental treatment?" was used to assess the self-perceived need for treatment. Results: Of the adolescents, $55.9 \%$ were female and $47.1 \%$ had an average family income of 1-3 minimum wages. The majority $(87.40 \%)$ presented normative needs. Regarding self-perception, $74.60 \%$ reported a need for dental treatment. There was significant positive agreement between positive self-perceived assessment of dental treatment needs and normative assessment. The sensitivity value was $76.90 \%$, and specificity was $40.90 \%$. The positive predictive value was $90 \%$, whereas the negative predictive value was $20.30 \%$. Adolescents presenting dental caries had a $24 \%$ higher prevalence of self-perceived need for dental treatment. The results of this study showed strong agreement between the need 
for self-perceived treatment and the need for clinical treatment. Conclusions: The positive self-perception of the need for dental treatment in young people can be used as an instrument to evaluate oral health conditions, since it can be used to meet their normative needs.

Keywords: normative dental treatment needs, perceived dental treatment needs, questionnaires, dental caries, gingivitis, trauma, adolescents.

\section{Background:}

Self-perception of treatment needs can be used to identify people who need clinically defined treatment, by prioritizing services according to the impact of the need, and by planning services to meet their needs better. Assessment of needs in dentistry has focused mainly on needs defined normatively and professionally.

Self-perception is divided into self-perception of health, self-perception of health needs and self-perception of treatment needs. Self-perception of health is the individual's understanding of his health condition ${ }^{1}$, representing his subjective perspectives $^{2}$. The self-perception of health needs may be related to the beliefs and knowledge of the affected person, influenced by psychological, socioeconomic and cultural factors ${ }^{3}$, and also by the values of those responsible for the well-being of this individual ${ }^{4}$. The self-perception of the need for treatment may be related to the presence of pain or discomfort ${ }^{5}$. Often, self-perceived need for dental treatment indicates the impact that the disease has on the individual ${ }^{6}$.

The clinical indicators (normative need) that usually guide the evaluation of an individual's need for treatment ${ }^{7}$ serve only to identify a disease. That is to say, they point out the number of dental services that must be performed for people to stay or become healthy, but do not consider the patient's attitudes and behaviors ${ }^{3}$. 
Indexes such as DMFT (decayed, missing and filled teeth) indicate only the extent and type of treatment already offered to the patient, as well as his difficulty in obtaining adequate and accessible oral health services ${ }^{8}$. To date, few studies have investigated the relationship between the self-perceived treatment need and the normative need for dental treatment. In one of the first studies on the subject ${ }^{9}$, no association was found, but more recent studies have indeed found a relationship $p^{7,10}$, thus concluding that questionnaire and interview data are valid measures of oral health status.

Accordingly, the present research compared the questionnaire data with the need for normative treatment. The authors conducted an investigation that provided information on perceived and clinically evaluated treatment needs in a population of adolescents. A comparison between the perceptions of dental treatment need and the normative assessments made by a dentist was performed to assess the level of agreement and association between clinical need and self-perceived need for dental treatment in adolescents.

\section{Methods:}

A cross-sectional school-based study was conducted. The database used was obtained from previous research ${ }^{11}$, which included an analysis of the oral health profile of 1771 school-going adolescents aged 15 to 19 years, from 36 municipalities with fewer than 50 thousand inhabitants in southern Brazil, carried out between June and December 2011.

The municipalities were selected according to the objectives of the main research. A total of 125 schools (98 urban and 27 rural; 5 private and 120 public) participated in the study. The sample size was calculated using the Decayed 
Missing Filled Teeth (DMFT) means, based on the same municipalities, selected from Brazil's national health survey conducted in $2009^{12}$.

The required sample of 1771 adolescents was found by estimating a level of significance of 0.05 and a power of $95 \%$, a non-response rate of $20 \%$ and a design effect of 1.5. The sample was distributed by a weighted average attributed among different schools, and student selection was performed using a systematic, random process. A pilot study with 102 students was carried out to train and calibrate the examiners, and assess the suitability of the research instruments.

Data were collected through questionnaires and clinical oral examinations performed under artificial light, using flat mirrors and probes, following the World Health Organization criteria ${ }^{13,14}$. After the informed consent forms were signed and the questionnaires were completed, the clinical exams were performed by four previously trained and calibrated dentists.

The sociodemographic variables used included sex (male and female), age (15 to 19 years old), monthly family income (up to 1 minimum wage; 1 to 3 minimum wages; and more than 3 minimum wages), based on the current minimum wage at the time of data collection (US\$327.92), and maternal years of schooling (up to 4 years; 5 to 9 years; and 10 years or more).

The self-perceived need for dental treatment was assessed with the question: "Do you think you currently need dental treatment?" ("yes" or "no"). After answering the questionnaire, the adolescents were examined for presence of caries, gingival bleeding, and dental trauma, as well as the recommended need for orthodontic treatment. 
The criteria recommended by the WHO for the condition of the dental crown and the need for treatment were related to dental caries, using scores from 0 to 9 , as follows: healthy tooth (0), carious crown (1), restored and carious crown (4), tooth missing for other reasons (5), sealant (6), bridge or crown support (7), unruptured crown (8), and trauma and excluded tooth (9). Data analyses were performed by classifying the variable as: 0 (no need); and 1 (categories 1,2,3,4,5,6,7,8).

The indication of the treatment was performed after the condition of the crown was recorded, using the following numerical codes: 0 (no need), 1 (need for filling of 1 side), 2 (filling of 2 or more sides), 3 (need for crown), 4 (veneers), 5 (pulp treatment and filling, 6 (extraction), 7 (remineralization), 8 (sealant) and 9 (no information). The need for treatment variable was categorized into 0 (no need), and 1 (categories $1,2,3,4,5,6,7,8$ ).

The gingival condition (bleeding and presence of calculus or pouch) was evaluated using the Community Periodontal Index (CPI). Only the conditions of absence (0) or presence (1) of gingival bleeding or dental calculus were used for this study. The mouth was divided into six sextants for the purpose of index registration. The observed condition was recorded in boxes of the representative sextant sheet after probing six index teeth of each sextant (teeth 16,11,26,36,31 and 46).

A tooth missing part of its coronary surface as a result of trauma, and having no evidence of caries, was considered as traumatized. The following adaptation of the dental trauma classification proposed by the World Health Organization was used to perform this evaluation: healthy tooth/without trauma (0); with enamel fracture (1); enamel and dentin fracture (2); enamel fracture and dentin with pulp exposure (3); and tooth loss due to trauma (4).The dental trauma variable for performing data analysis was categorized into 0 (no need) and 1 (categories 1,2,3,4). 
The criteria for determining the clinical need for orthodontic treatment used in this study were those recommended by the Dental Aesthetic Index (DAI). This index evaluates the following factors: number of incisors, canines and missing premolars, crowding in the incisor region, spacing in the incisor region, diastema, maxillary misalignment, mandibular misalignment, anterior maxillary overjet, mandibular overjet, anterior open bite, and anteroposterior molar ratio. After evaluating the clinical need, an equation was applied to calculate the values obtained (WHO, 1997), categorizing the need according to the conditions of normal occlusion and the malocclusion defined, either severe or incapacitating. The outcome of the DAI evaluation of treatment needs according to the factors assessed was: no or little need for treatment (DAI $\leq 25$ ), elective need for treatment $(\mathrm{DAI}=26-30)$, and highly recommended need for treatment (DAI $\geq 31$ ).

A new variable called normative need was created to measure clinical treatment needs. It included the treatment needs for caries, bleeding, restorative treatment and trauma.

The dependent variable was the self-perceived treatment need. The independent variables were the following: presence of caries, need for restorative treatment, presence of bleeding, trauma, need for orthodontic treatment, female, income, maternal educational level, and normative need.

Data analysis was carried out using the Statistical Package for Social Sciences (SPSS) for Windows (18). It included the frequency distribution of the studied variables and the Pearson's chi-square test. The prevalence ratio was calculated (95\% confidence interval) by Poisson regression with robust univariate and multivariate variance. The level of statistical significance of all the analyses was set at $5 \%(p<0.05)$. 
Sensitivity, specificity, positive predictive value (PPV) and negative predictive value (NPV) of self-perceived need for dental treatment were also calculated in relation to the normative needs. The present study was submitted to and approved by the Research Ethics Committee of the Dental School of the Federal University of Rio Grande do Sul (no. 15370) and the Research Ethics Committee of the School of Public Health of Rio Grande do Sul State (No. 624/11). All individuals identified with normative needs were referred to the public health centers of their cities.

\section{Results:}

Of the 1771 adolescents evaluated, 1470 answered the question about selfperception. Only the latter individuals were considered in this study. There was a predominance of females (Table 1). The average family income was 1 to 3 Brazilian minimum wages in $47.1 \%$ of the group examined, and more than 3 minimum wages in a little over $1 / 3$ of the group. The majority of the participants had mothers with 5 to 9 years (39.3\%) of schooling, whereas $35.5 \%$ had mothers with more than 10 years of schooling.

Regarding the need for self-perceived treatment, $71 \%$ reported that they perceived the need for dental treatment; this perception was higher in the female sex $(74.8 \%)$ than the male sex (66.2\%). Regarding caries, almost $1 / 3$ of the patients had one or more decayed teeth. Concerning bleeding, almost half of the group presented bleeding in at least one sextant. More than $70 \%$ of the analyzed patients presented no need for restorative treatment. In 1155 young people (78.6\%), there was no diagnosis of trauma. In $17.6 \%$, the diagnosis was a highly recommended need for orthodontic treatment. The prevalence of normative treatment need was higher for bleeding, followed by caries. When the normative 
needs (caries, bleeding, need for restorative treatment and trauma) were combined into a single variable called normative need, the sample dropped from 1470 to 1182 participants, including only valid questionnaire answers and clinical exams. Of these (Table 2), 881 had a self-perceived need for dental treatment. Dentists identified needs in 1033 adolescents.

Of all the students who had a normative dental treatment need $(n=1033 ; 87.40 \%)$, 794 (76.90\%) perceived this need. Among the 149 students (12.60\%) who did not need any standard treatment, 60 adolescents (40.90\%) perceived that they did not need dental treatment. The rest of this group ( $n=89 ; 59,10 \%)$ perceived that they did need dental treatment.

Of the 881 patients $(74.60 \%)$ who perceived that they needed dental treatment, $792(90 \%)$ were right. Of the 301 adolescents (25.40\%) who self-perceived having no need, 61 students $(20.30 \%)$ really did not need treatment. The remaining 240 adolescents (79.70\%) perceived themselves as not needing dental treatment, whereas they actually did need clinically identified dental treatment.

The positive predictive value observed was very high (Table 2) for both sexes, and the negative predictive value was very low, also for both sexes. Regarding gender, women perceived the need for treatment more than men, but men presented more normative needs than women (Table 2).

Poisson regression analysis (Table 3 ) shows that the factors independently associated with self-perceived need for dental treatment were presence of caries, presence of bleeding, need for orthodontic treatment and the female sex (that most perceives the need for dental treatment). Family income and mother's 
schooling did not significantly influence the self-perceived need for dental treatment among the adolescents studied.

Evaluating the presence of caries variable, it was observed that adolescents with dental caries had a $24 \%$ higher prevalence of self-perceived need for dental treatment $(95 \% \mathrm{Cl}=1.08-1.43)$. Adolescents who were diagnosed with a need for orthodontic treatment had a $13 \%$ higher prevalence of self-perceived need for treatment $(95 \% \mathrm{Cl}=1.02-1.25)$, and students with bleeding in at least one sextant showed a $12 \%$ higher prevalence of self-perceived need for dental treatment $(95 \%$ $\mathrm{Cl}=1.01-1.23)$. The female gender also showed statistically significant results, considering that women had an $11 \%$ higher prevalence of self-perceived need for dental treatment $(95 \% \mathrm{Cl}=1.00-1.22)$.

\section{Discussion}

The data reported above suggest that self-perceived interviews are useful for assessing the oral health status and treatment needs of individuals. Selfassessment and professional assessment identified a closely matching number of people with dental treatment needs. Thus, it can be concluded that there is a strong association between a need for dental treatment that is self-perceived and the need for normative dental treatment in schoolchildren aged 15 to 19 years. The agreement between self-perceived need and clinical treatment need was $90 \%$ (sensitivity).

Variables that may not be related to pain were used in this study. Nevertheless ${ }^{15}$, asymptomatic diseases were perceived satisfactorily, following clinical diagnosis ${ }^{10,16}$. A few cases of non-clinically identified self-perceived treatment 
needs were observed. These may be related to flecks and pigmentation perceived in self-diagnosis ${ }^{17}$. The perceived incidence of a disease also depends on the true incidence and its degree of recognition ${ }^{18}$. Whereas a dental surgeon evaluates the condition based on the absence or presence of disease, a patient more easily observes the symptoms and the functional and social problems caused by the presence of a disease ${ }^{19}$, thereby explaining the difference found between selfperceived evaluation and normative evaluation.

In the present study, adolescents with clinically observed caries had a $24 \%$ higher self-perception prevalence of dental treatment. Most of the time, the reason why people do not seek dental care is that they do not perceive its need. The perception of the oral health condition and the importance given to it are useful health indicators, since they synthesize the health condition, the values and the cultural expectations that influence an individual's behavior ${ }^{20}$. This is related to the negative predictive value observed in this study, where $80 \%$ of the sample who perceived no treatment need actually did present a clinical need.

Despite the variety of etiological factors involved in the cause of tooth pain, its most common agent is dental caries ${ }^{21}$, observed in almost $1 / 3$ of those evaluated in the present study. Moreover, the results for the Poisson regression showed that a greater number of adolescents perceived that they needed treatment based on their caries experience. Dental pain is highly prevalent in children ${ }^{22}$, and may have a deep effect on overall health and quality of life ${ }^{23}$.

This study worked with 15- to 19-year-old students. The fact that the selfperceived need for dental treatment was high in this investigation could be attributed to the age of this group. "Older" adolescents are in an advanced process of developing critical awareness, in relation to the younger ones ${ }^{24}$. In older teens, 
sociability and concern about aesthetics elicit the need for self-care, mainly in girls. This explains the result of the higher prevalence of their self-perceived dental treatment need, the presence of bleeding, and the need for orthodontic treatment found in this research.

In addition to the higher prevalence of self-perceived need for dental treatment, the female sex also showed greater agreement between the need for normative treatment and the need for self-perceived treatment, with a sensitivity of $81.30 \%$ compared with men $(71.80 \%)$. This may be explained by aspects of social and cultural norms. Women perceive their oral health needs more frequently than men, seeking and paying more attention to health services ${ }^{25,26}$. Unlike other studies ${ }^{1,6}$, the present research has shown that the family's average income and the mother's schooling do not significantly interfere with the adolescent's self-perception.

This study presents some limitations. Because of its cross-sectional design, it does not allow establishing whether the perceived need changes in populations as the normative levels of these parameters change. The self-assessment of health may also be associated with the emotional state and the feelings of the participants at the time studied ${ }^{27}$, and may be sensitive to uncertainties and bias of interpretation ${ }^{28}$. Whereas the findings of this study suggest a relationship between perceived need and normative need, the correlation between the two should be investigated in populations with different levels of need.

The agreement between normative and self-perceived dental treatment needs, by Brazilian students aged 15 to 19 years, even without the presence of painful symptomatology, was found to be very satisfactory in this study. This indicates that subjective measures are useful to identify groups who need clinically defined treatment or health promotion actions. 
However, it should be acknowledged that the self-perception of 'no dental treatment need' was not in agreement with the clinically evaluated need in more than half of the adolescents.

\section{List of abbreviations}

DMFT- decayed, missing and filed teeth

WHO- World Health Organization

CPI- Community Periodontal Index

DAI- Dental Aesthetic Index

SPSS- Statistical Package for Social Sciences

PPV- Positive Predictive Value

NPV- Negative Predictive Value

\section{Declarations}

-Ethics approval and consent to participate: The present study was submitted to and approved by the Research Ethics Committee of the Dental School of the Federal University of Rio Grande do Sul (no. 15370) and the Research Ethics Committee of the School of Public Health of Rio Grande do Sul State (No. 624/11).

-Consent for publication: Not applicable

-Availability of data and materials:The datasets generated during and/or analysed during the current study are available in the LUME repository, https://lume.ufrgs.br/handle/10183/105242

-Competing interests: "The authors declare that they have no competing interests"

-Funding; Not applicable 
-Authors' contributions: All authors (FCLD, ABM, HEC, CA) had substantial contributions to the conception or design of the work; and acquisition, analysis, or interpretation of data for the work; and drafting the work or revising it critically for important intellectual contente and final approval of the version to be published. All authors have read and approved the manuscript.

-Acknowledgements: not applicable

-Authors' information (optional) 


\section{$\underline{\text { References }}$}

1. Almeida JRS, Alencar CH, Barbosa JC, Dias AA, Almeida MEL. Autopercepcao de pessoas acometidas pela hanseniase sobre sua saúde bucal e necessidade de tratamento. CienSaude Colet. 2013;18(3):817-826. doi:http://dx.doi.org/10.1590/S1413-81232013000300027

2. Atchison KA, Gift HC. Perceived Oral Health in a Diverse Sample. AdvDent Res. 1997;11(2):272-280. doi:10.1177/08959374970110021001

3. Sheiham A. A determinação de necessidades de tratamento odontológico: uma abordagem social. In: Pinto VG, ed. SaúdeBucalColetiva. Vol 1. ; 2000:223-250. doi:10.1590/S1516-18462008000300012

4. Andersen RM, Davidson P. Ethnicity, aging, and oral health outcomes : a conceptual framework. Adv Dent Res. 1997;11(2):203-209.

5. Seremedi K, Koletsi-Kounari H, Kandilotou H. Self-reported and clinicallydiagnosed dental needs: determining the factors that affect subjective assessment. Oral HealPrevDent. 2009;7(2):183-190.

6. Martins AMEBL, Barreto SM, Pordeus IA. Fatores relacionados a autopercepção da necessidade de tratamento odontológico entre idosos. RevSaude Publica. 2008;42(3):487-496. https://www.scopus.com/inward/record.uri?eid=2-s2.048849100772\&partnerlD=40\&md5=8ba9beb479df1 ca7f181b5b12899339c\% OAhttps://www.scopus.com/inward/record.uri?eid=2-s2.0$58149196472 \&$ partnerlD=40\&md5=cf0f9cfb8ea1 be83e7f48b1b73eafea5.

7. Nascimento AR do, Andrade FB de, César CC. Validade e utilidade da autopercepção de necessidade de tratamento odontológico por adultos e idosos. Cad SaudePublica. 2015;31(8):1765-1774. doi:10.1590/0102$311 \times 00150214$

8. Roncalli AG, Tsakos G, Sheiham A, De Souza GC, G Watt R. Social determinants of dental treatment needs in Brazilian adults. BMC Public Health. 2014;14(1):1-11. doi:10.1186/1471-2458-14-1097

9. Robinson PG, Nadanovsky P, Sheiham A. Can questionnaires replace clinical surveys to assess dental treatment needs of adults? J Public Health Dent. 1998;58(3):250-253. doi:10.1111/j.1752-7325.1998.tb03002.x

10. Keboa M, Madathil S, Nicolau B. Do perceived dental treatment needs reflect objectively measured needs in children ? Int $\mathrm{J}$ Pediatr. 2016;271(February). doi:10.22038/ijp.2016.6446

11. Ely HC, Abegg C, Celeste RK, Pattussi MP. Impacto das equipes de saúde bucal da Estratégia da Saúde da Família na saúde bucal de adolescentes do sul do Brasil. CienSaude Colet. 2016;21(5):1607-1616.

doi:10.1590/1413-81232015215.07822015

12. Ministério da Saúde. Pesquisa Nacional de Saude Do Escolar: PeNSE. Rio 
de Janeiro; 2009.

http://www.ibge.gov.br/home/estatistica/populacao/pense/pense.pdf.

13. Organization WH. Oral Health Surveys: Basic Methods. 5th ed.; 2013.

14. Organization WH. Calibration of Examiners for Oral health Epidemiological surveys. 1993.

15. Locker D, Jokovic $A$. Using subjective oral health status indicators to screen for dental care needs in older adults. CommunityDent Oral Epidemiol. 1996;24(6):398-402. doi:10.1111/j.1600-0528.1996.tb00887.x

16. Jahnke MM, Ponte ME, Abegg C, Fontanive VN, Davoglio R. Necessidade de tratamento odontologico autopercebida e normativa em individuos de tres distritos sanitarios de Porto Alegre-RS. RFO. 2013;18(3):271-276. doi:http://dx.doi.org/10.5335/rfo.v18i3.3108 *

17. Honkala E. Promotion with children and adolescents. In: Oral Health Promotion. London: Oxford Medical Publications; 1993:169-187.

18. Helman C. Fatores culturais em epidemiologia. In: Cultura, Saúde e Doença. 4a ${ }^{\text {a }}$ Porto Alegre; 2003:282-295.

19. Bortoli D, Locatelli FA, Fadel CB, Baldani MH. Associação entre percepção de saúde bucal e indicadores clínicos e subjetivos : estudo em adultos de um grupo de educação continuada da terceira idade. UEPG BiolHealSci. 2003;9(3/4):55-65.

20. Silva S, Fernandes R. Autopercepção das condições de saúdebucal por idosos. Rev SaudePublica. 2001;35(4):349-355. doi:10.1590/S003489102001000400003

21. Rosa AR, Abegg C, Ely H. Sense of Coherence and Toothache of Adolescents from Southern Brazil. J Oral Facial Pain Headache. 2015;29(3):250-256. doi:10.11607/ofph.1383

22. Slade G. Epidemiology of dental pain and dental caries among children and adolescents. Community Dent Health. 2001;18(4):219-227.

23. Petersen PE, Bourgeois D, Ogawa H, Estupinan-Day S, Ndiaye C. The global burden of oral diseases and risks to oral health. Bull World Health Organ. 2005;83(9):661-669. doi:/S0042-96862005000900011

24. Fonseca EP, Ferreira EF, Abreu MHNG, Palmier AC, Vargas AMD. Relação entre condição gengival e fatores sociodemograficos de adolescentes residentes em uma região brasileira. CienSaude Colet. 2015;20(11):33753384. doi:10.1590/1413-812320152011.00142015

25. Courtenay WH. Constructions of masculinity and their influence on men's well-being: A theory of gender and health. SocSci Med. 2000;50(10):13851401. doi:10.1016/S0277-9536(99)00390-1

26. Lacerda JT de, Castilho EA de, Calvo MCM, Freitas SFT de. Saude bucal e o desempenho diário de adultos em Chapecó, Santa Catarina, Brasil. CadernoSaúdePública. 2008;24(8):1846-1858. 
27. Ewles L, Simnett I. Concepts and determinants of health. In: Limited AP, ed. Promoting Health: A Practical Guide. Third Edit. London; 1995:3-19.

28. Souza DE, Almeida Filho N. Medindo Saúde. In: Epidemiologia e Saúde: Fundamentos, Métodos, Aplicações. Rio de Janeiro: Editora Guanabara Koogan; 2012:118-126. 


\section{Supplementary Files}

This is a list of supplementary files associated with this preprint. Click to download.

- STROBEchecklistcrosssectionalPREENCHIDO.docx

- Titlepagenew.docx 